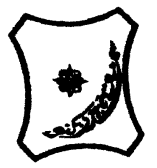

Bayero Journal of Pure and Applied Sciences, 13(2): 13 -21

Received: September, 2020

Accepted:November, 2020

ISSN $2006-6996$

\title{
INFLUENCE OF PHYSICAL ACTIVITY LEVEL AND BODY ADIPOSITY ON LUMBAR MULTIFIDUS MUSCLE FAT INFILTRATION OF LOW BACK PAIN INDIVIDUALS
}

\author{
Dambele, M. Y., ${ }^{1}$ Yamsat, N. A., ${ }^{2}$ Raheem, S. ${ }^{3}$ and Akindele, M.O. ${ }^{2 *}$ \\ 1. Department of Medical Radiography, Faculty of Allied Health Sciences, Bayero University Kano, Kano \\ State, Nigeria. \\ 2. Department of Physiotherapy, Faculty of Allied Health Sciences, Bayero University, Kano, Kano \\ State, Nigeria. \\ 3. Department of Physiotherapy, National Orthopaedic Hospital, Dala, Kano, Kano State, Nigeria. \\ Corresponding Author: Email: mukaakin@gmail.com
}

\begin{abstract}
The stability of the spinal column is largely dependent on the integrity of the spinal muscles, especially the multifidus muscle. However, this important role of the multifidus muscle might be compromised due to both mechanical and non-mechanical causes leading to change in its contents, fat deposition and reduction in the cross-sectional area.This study was carried out to determine the influence of physical activity level and body adiposity indices on lumbar multifidus muscle (LMM) fatty infiltrationamong individuals with low back pain (LBP). This was a cross-sectional study in which 94 participants, male and female samples with non-specific LBP were recruited conveniently and assessed for LMM fat infiltration, pain intensity, functional disability, physical activity and socio-demographic variables. There were positive and moderate correlations between LMM fatty infiltration and body mass index (BMI) $(r=0.575, p=0.001)$, waist circumference $(W C)(r=0.514, p=0.001)$ and gender $(r=0.409, p=0.001)$ for normally distributed data using Pearson moment correlation coefficient. For not normally distributed variables, LMM fatty infiltration was moderately and positively correlated with gender $(r=0.422, p=0.001)$, \%body fat $(r=0.621$, $p=0.001)$, visceral fat $(r=0.470, p=0.0001)$, Oswestry Disability Index (ODI) $(r=0.238$, $p=0.021)$ and visual analogue scale $(V A S)(r=0.232, p=0.024)$ respectively. However, there was a weak negative correlation between $L M M$ fatty infiltration and occupation ( $r=-0.206$, $p=0.046$ ). There were significant differences between male and female multifidus fat infiltration and body adiposity indices. There was a positive relationship between multifidus fatty infiltration and BMI, gender, \%body fat, visceral mass, ODI and VAS, while we observed a negative relationship between lumbar multifidus fatty infiltration and occupation. Furthermore, the best correlate of lumbar multifidus fatty infiltration was \%body fat.

Keywords: Multifidus, Muscle, fatty infiltration, low back pain, adiposity, physical activity
\end{abstract}

\section{BACKGROUND}

Low back pain (LBP) is an extremely common symptom experienced by people of all ages and a leading cause of disability worldwide (Hartvigsen et al., 2018). In 2015, the global point prevalence of activity-limiting LBP was $7.3 \%$, which implies that 540million people were affected at any one time (Hoy et al., 2012). The largest increase in the disability caused by LBP in the last few decades have occurred in low income and middle income countries including Africa, Asia and the Middle East where health and social systems are not well equipped (Hoy et al., 2015). In Africa, the lifetime prevalence of LBP has been estimated at around $28 \%-74 \%$, which is almost comparable to the rates in Western societies (Louw et al., 2007). In Nigeria, one-year LBP prevalence has been reported between 33\% and 74\% among the adult population who are mainly workers (Bello and Adebayo, 2017). 
BAJOPAS Volume 13 Number 2,December, 2020

LBP is a multifactorial disorder with many possible etiologiesand has been attributed to several biophysical factors while its maintenance associated with several psychosocial factors (Ramond-Roquinet al., 2015). According to some researchers, large groups of the disorders of the lower back are predominantly mechanically induced and they lead to a maladaptive process that maintains the ongoing pain and can result in functional deficits (O'Sullivanet al., 2003). There is evidence that individuals with LBP have altered motor control of specific muscles of the trunk particularly the transversus abdominis muscle and lumbar multifidus muscle (LMM) when the stability of the spine is challenged in dynamic tasks (i.e. perturbations) (Hodges and Richardson, 1998; Hodges \& Richardson, 1999). Furthermore, studies have shown that abnormalities in the brain (altered brain structure and function) (Wand et al., 2011), changes in lumbar tactile acuity (Luomajoki and Moseley, 2011), decreases in spinal mobility (Hodgeset al.,2009), and compromises in postural control (Moket al.,2007) were found to be present in patients' LBP compared to asymptomatic individuals.

Another important structural change linked with LBP is fat infiltration of the LMM. Fat infiltration of LMM is defined as the histological change in the distribution of fiber types and a reduction in the size of the muscle in patients with CLBP (Mannion, 1999) and intervertebral disc herniation (Cambellet al,1998). Lumbar muscle when degenerated may compromise spinal stability and jeopardize spinal health, potentially leading to further injury as described by Panjabi (1992). Fatty infiltrates arise because of atrophy of the skeletal musculature (Hideset al.,2008). A study by Kalichmanet al., (2010), suggested that altered paraspinal morphology such as fat penetration in the LMM might be related to increasing LBP and consequently low physical activity. In the same vein, Hides et al., (1996) reported that LMM with atrophy in the lower back on the painful side did not recover automatically following appropriate treatment protocols, which made them suggest that fatty infiltrates in the LMM have some correlation with persisting LBP. In contrast, Hultman et al.(1993) found no difference in paraspinal CSA or density, which is a substitute for fatty infiltration on CT during remission of intermittent LBP compared to healthy controls.

Morphological studies have shown an association between LMM fatty infiltration and LBP patients in high-income countries (Kelleret al., 2004; Le Huecet al.,2005). There is inconsistency in the relationship between high BMI, LMM fatty infiltration, and postural instability. Hence,Storheim, et al. (2017) advised on further prospective studies that will look into this relationship. Unfortunately, only a few studies on the multifidus fat infiltration have been conducted in sub-Saharan Africa bearing in mind that there is a high prevalence of excess weight and obesity among black Africans, especially Nigerians (Akindeleet al., 2016), such that slow learning among school children has been linked to obesity and overweight in Africa (Adomet al.,2017). A study was needed therefore to ascertain the influence of physical activity and body adiposity on LMM fatty infiltration among low back pain individuals from low resource African setting.

\section{MATERIALS AND METHODS}

The Ethics and Research Committee of Aminu Kano Teaching Hospital (AKTH) approved this cross-sectional study with number NHREC/21/08/2008/AKTH/EC/2631. The participants for this study were patients with nonspecific low back pain attending general outpatient departments of Surgery and Physiotherapy Departments of AKTH using a purposive sampling technique. The setting for this study was a tertiary health institution with more than 700-bed spaces for admission and many outpatient specialty clinics. Participants with a previous history of spinal surgery, pregnancy, TB of the spine and those with a known cause of LBP were excluded from this study. Each participant was screened for NSLBP once referred for physiotherapy by a Physiotherapist who specializes in LBP management. A total number of 94 non-specific LBP individuals 18 years and above participated in this study, which formed $97.92 \%$ of the calculated sample size.

The instruments used for the collection of data for this study were Oswestry Disability Index (ODI) for low back pain disability, International Physical Activity Questionnaire (IPAQ) for physical activity level, diagnosticultra sound machine for LMM fat imaging, weighing scale to measure the weight and visceral fat of the participants and Stadiometer (Upsurge Medical Stadiometer ZT120, Made in England)to measure the participants' height. Medison Accuvix V10 ultrasound scanner with a 3.7 MHz Curvilinear probe was used to determine the fat infiltration in the Lumbar Multifidus Muscle. Tanita Ironman electronic weighing scale (TANITA BC-549 plus IRONMAN ${ }^{\mathrm{R}}$, Tanita Corp., Tokyo, Japan), tape measure and Stadiometer were used. 
BAJOPAS Volume 13 Number 2,December, 2020

Tanita Ironman electronic weighing scale was used to measure the participants' weight, \%body fat and the visceral mass. Standard procedures as detailed in the manuals of the ultrasound machine, Tanita Ironman electronic weighing scale and Stadiometer were followed while collecting data.

\section{Data analysis}

Descriptive statistics of frequency, percentage, mean and standard deviation were used to reduce age, gender, and other sociodemographic details. Test of normality was carried out using ShapiroWilk and normally distributed variables were analysed using Pearson correlation coefficient while Spearman rho correlation coefficient was used for not normally distributed variables. Student's t-test was used to determine the differences between clinical variables among genders. Other variables were summarized with descriptive statistics. Multiple regression analysis was used to determine the predictor of lumbar multifidus fat infiltration using sociodemographic and body adiposity variables as independent variables while fat infiltration was used as a dependent variable. The data obtained was analyzed using the statistical package for social sciences (SPSS version 20.0) at a significant level of 0.05

\section{RESULTS}

A majority of the participants were male $(55.3 \%)$, married $(84 \%)$, had tertiary education $(53.2 \%)$ whereas a significant number were self-employed (46.8\%)and obese (37.2\%). The sociodemographic characteristics of the participants are fully shown in Table 1 below.

Table1. Participants' socio-demographic characteristics

\begin{tabular}{lll}
\hline Variable & Frequency & Percentage (\%) \\
\hline Gender: & & \\
Male & 52 & 55.3 \\
Female & 42 & 44.7 \\
Marital Status: & & \\
Married & 79 & 84 \\
Single & 12 & 12.8 \\
Divorced & 1 & 1.1 \\
Widowed & 2 & 2.1 \\
& & \\
Education Level: & & 8.5 \\
Not Educated & 8 & 9.6 \\
Primary & 9 & 28.7 \\
Secondary & 27 & 53.2 \\
Tertiary & 50 & \\
& & 13.8 \\
Occupation & & 36.2 \\
Unemployed & 13 & 46.8 \\
Employed & 34 & 3.2 \\
Self Employed & 44 & \\
Retired & 3 & \\
\hline
\end{tabular}

Participants' clinical characteristics of pain, physical activity and disability distributions

Table 2 shows the participants' overall clinical characteristics in terms of pain at the lower back and physical activity levels. The table shows that more participants $(47.9 \%)$ experienced severe pain, few $(20.2 \%)$ experienced worst pain, while others $(31.9 \%)$ had moderate pain based on the visual analogue scale measurement with 4.41 1.59 mean and standard deviation respectively. Based on the physical activity level, most of the participants $(55.3 \%)$ recorded low MET minutes, few $(25.5 \%)$ were moderately active, while very few $(19.1 \%)$ were highly active and generally within $933.11 \pm 106.82$ mean and standard deviations respectively.

The disability index measured indicated that some are minimally disabled (19.1\%), moderately disabled (59.65), severely disabled $(17.0 \%)$, while others $(4.3 \%)$ were at the crippled stage. 
BAJOPAS Volume 13 Number 2,December, 2020 The mean and standard deviation for the disability status was found to be $36.19 \pm 12.39$. There were statistically significant differences between males and females when their lumbar multifidus \%fat, BMI, WC, WHR and visceral fat were compared as shown in Table 2 below.

Table 2: Clinical Variables of the Participants

\begin{tabular}{|c|c|c|c|c|c|c|c|}
\hline \multirow[t]{2}{*}{ Variable } & \multicolumn{2}{|c|}{ Male } & \multicolumn{2}{|c|}{ Female } & \multirow[t]{2}{*}{$\mathbf{m} \pm \mathbf{s d}$} & \multirow[t]{2}{*}{$\mathbf{t}$} & \multirow[t]{2}{*}{ p-value } \\
\hline & $\mathbf{n}$ & $(\%)$ & $\mathbf{n}$ & $(\%)$ & & & \\
\hline Multifidus \% fat & & & & & $7.10 \pm 1.90$ & 4.30 & $0.001 *$ \\
\hline Normal & 43 & 45.7 & 25 & 26.6 & & & \\
\hline Slight & 9 & 9.6 & 17 & 18.1 & & & \\
\hline Severe & & & & & & & \\
\hline BMI & & & & & $27.71 \pm 5.24$ & 4.84 & $0.001 *$ \\
\hline Underweight & 2 & 3.8 & 0 & 0 & & & \\
\hline Normal weight & 22 & 42.3 & 4 & 9.5 & & & \\
\hline Overweight & 16 & 30.8 & 15 & 35.7 & & & \\
\hline Obese & 12 & 23.1 & 23 & 54.8 & & & \\
\hline WC & & & & & $7.10 \pm 1.90$ & 3.01 & $0.003^{*}$ \\
\hline Waist hip ratio & & & & & $27.71 \pm 5.24$ & 0.96 & 0.342 \\
\hline Low risk & 45 & 86.5 & 10 & 23.8 & & & \\
\hline Moderate risk & 6 & 11.5 & 3 & 7.1 & & & \\
\hline High risk & 1 & 1.9 & 29 & 69. & & & \\
\hline$\%$ body fat & & & & & $7.10 \pm 1.90$ & 13.35 & $0.001 *$ \\
\hline Visceral mass & & & & & $27.71 \pm 5.24$ & 2.57 & $0.013^{*}$ \\
\hline Healthy & 45 & 86.5 & 37 & 88.1 & & & \\
\hline Excess & 7 & 13.5 & 5 & 11.9 & & & \\
\hline Pain intensity & & & & & $7.10 \pm 1.90$ & 0.73 & 0.471 \\
\hline Mild pain & 31 & 59.6 & 23 & 54.8 & & & \\
\hline Moderate pain & 17 & 32.7 & 17 & 40.5 & & & \\
\hline Severe pain & 4 & 7.7 & 2 & 4.8 & & & \\
\hline Disability index & & & & & $27.71 \pm 5.24$ & 0.59 & 0.554 \\
\hline Minimal disability & 4 & 7.7 & 5 & 11.9 & & & \\
\hline Moderate disability & 39 & 75 & 27 & 64.3 & & & \\
\hline Severe disability & 7 & 13.5 & 7 & 16.7 & & & \\
\hline Crippling LBP & 1 & 1.9 & 3 & 7.1 & & & \\
\hline Bedbound LBP & 1 & 1.9 & 0 & 0 & & & \\
\hline PAL & & & & & $7.10 \pm 1.90$ & 0.07 & 0.943 \\
\hline Low PAL & 30 & 57.7 & 22 & 52.4 & & & \\
\hline Moderate PAL & 10 & 19.2 & 14 & 33.3 & & & \\
\hline High PAL & 12 & 23.1 & 6 & 14.3 & & & \\
\hline
\end{tabular}

Key: BMI=body mass index, $\mathrm{WC}=$ waist circumference, $\mathrm{PAL}=$ physical activity level,

There were positive and moderate correlations between LMM fatty infiltration and BMI ( $r=0.575$, $p=0.001)$, WC $(r=0.514, p=0.001)$ and gender $(r=0.409, p=0.001)$ for normally distributed data using Pearson moment correlation coefficient. For not normally distributed variables, LMM fatty infiltration was moderately and positively correlated with gender $(r=0.422, p=0.001)$ \% \%ody fat $(r=0.621, p=0.001)$, visceral fat $(r=0.470, p=0.0001)$, ODI $(r=0.238, p=0.021)$ and VAS $(r=0.232, p=0.024)$ respectively. However, there was a weak negative correlation between LMM fatty infiltration and occupation $(r=-0.206$, $\mathrm{p}=0.046)$. 
BAJOPAS Volume 13 Number 2,December, 2020

Table 3: Relationships between LMMF and Sociodemographic and clinical Variables

\begin{tabular}{|c|c|c|c|c|c|c|c|c|c|}
\hline & LMMF & BMI & WC & \%Body fat & $\begin{array}{l}\text { Visceral } \\
\text { fat }\end{array}$ & ODI & VAS & Gender & Occupation \\
\hline \multicolumn{10}{|l|}{ LMMF } \\
\hline$r$ & 1 & & & & & & & & \\
\hline \multicolumn{10}{|l|}{$\begin{array}{c}\mathrm{p} \\
\mathbf{B M I}\end{array}$} \\
\hline$r$ & $+0.575^{*} *$ & 1 & & & & & & & \\
\hline$\underset{\mathbf{w C}}{\mathrm{p}}$ & 0.000 & & & & & & & & \\
\hline$r$ & $+0.514^{* *}$ & $0.804^{* *}$ & 1 & & & & & & \\
\hline$\underset{\text { \%Body fat }}{\mathrm{p}}$ & 0.000 & 0.000 & & & & & & & \\
\hline r & $+0.621 * *$ & $0.799 * *$ & $0.681 * *$ & 1 & & & & & \\
\hline $\mathrm{p}$ & 0.000 & 0.000 & 0.000 & & & & & & \\
\hline Visceral fat & & & & & & & & & \\
\hline$r$ & $+0.470 * *$ & $+0.736 * *$ & $+0.705^{* *}$ & $+0.643 * *$ & 1 & & & & \\
\hline$\underset{\text { ODI }}{p}$ & 0.000 & 0.000 & 0.000 & 0.000 & & & & & \\
\hline$r$ & $+0.238^{*}$ & 0.065 & $+0.214^{*}$ & 0.100 & 0.140 & 1 & & & \\
\hline$\underset{\text { VAS }}{p}$ & 0.021 & 0.533 & 0.039 & 0.340 & 0.178 & & & & \\
\hline$r$ & $+0.232 *$ & 0.088 & 0.170 & 0.119 & 0.123 & $+0.691^{* *}$ & 1 & & \\
\hline $\begin{array}{l}\mathrm{p} \\
\text { Gender }\end{array}$ & 0.024 & 0.398 & 0.102 & 0.253 & 0.239 & 0.000 & & & \\
\hline$r$ & $0.422 * *$ & $+0.444 * *$ & $+0.380 * *$ & $+0.799 * *$ & $+0.302 * *$ & 0.054 & 0.095 & 1 & \\
\hline $\begin{array}{c}\mathrm{p} \\
\text { Occupation }\end{array}$ & 0.000 & 0.000 & 0.000 & 0.000 & 0.003 & 0.605 & 0.360 & & \\
\hline$r$ & $-0.206^{*}$ & -0.128 & -0.149 & $-0.299 * *$ & $0.211 * *$ & $-0.207^{*}$ & -0.159 & $-0.345^{* *}$ & 1 \\
\hline$p$ & 0.046 & 0.219 & 0.153 & 0.003 & 0.041 & 0.045 & 0.127 & 0.001 & \\
\hline
\end{tabular}


BAJOPAS Volume 13 Number 2,December, 2020

The researchers ran a multiple regression to predict how PA (METs) and body adiposity (BMI, WHR, waist circumference, \% body fat and visceral fat) influenced lumbar multifidus fatty infiltration among low back pain individuals. These variables statistically significantly predicted lumbar multifidus fatty, $F(9,84)=15.96, p=0.000$, $\mathrm{R}^{2}=0.426$. Only \%body fat statistically predicted lumbar muscle fatty infiltration $(p=0.004)$ as shown in Table 4 below.

Table 4: Predictors of Lumbar Multifidus Fat Infiltration

\begin{tabular}{lrrrrr}
\hline \multicolumn{1}{c}{ Predictors } & B & \multicolumn{1}{c}{ SEB } & \multicolumn{1}{c}{$\boldsymbol{\beta}$} & 95\% CI & p-value \\
\hline PA & -9.478 & 0.000 & -0.049 & $0.000-0.000$ & 0.564 \\
BMI & 0.057 & 0.065 & 0.157 & $0.148-0.103$ & 0.386 \\
WHR & -0.078 & 3.322 & -0.003 & $6.485-6.329$ & 0.981 \\
WC & 0.025 & 0.027 & 0.166 & $0.027-0.078$ & 0.341 \\
\%body fat & 0.067 & 0.023 & 0.407 & $0.022-0.112$ & $0.004 * *$ \\
Visceral fat & -0.023 & 0.063 & -0.047 & $0.148-0.103$ & 0.718 \\
VAS & 0.019 & 0.015 & 0.156 & $-0.010-0.048$ & 0.207 \\
AGE & 0.003 & 0.018 & 0.021 & $-0.032-0.039$ & 0.851 \\
\hline
\end{tabular}

Key: $\mathrm{PAL}=$ physical activity level, $\mathrm{BMI}=$ body mass index, $\mathrm{WHR}=$ waist-hip ratio, $\mathrm{WC}=$ waist circumference, VAS $=$ visual analogue scale

\section{DISCUSSION}

A majority of the participants were male, married, with half of them having tertiary education and less than halfself-employed. Most of the participants reported severe low back pain, low physical activity level and moderately disabled as a result of low back pain. There were significant differences between male and female multifidus fat infiltration, BMI, WC, \%body fat and the visceral mass. There was a positive relationship between multifidus fatty infiltration and BMI, gender, \%body fat, visceral mass, ODI and VAS, while the researchers observed a negative relationship between lumbar multifidus fatty infiltration and occupation. Furthermore, the best correlate of lumbar multifidus fatty infiltration was \%body fat.

The researchers observed differences in the body adiposity indices between male and female participants. This has been reported in the literature earlier; female gender has a higher \%body fat and deposition in different parts of the body (Karastergiouet al.,2012). This was earlier reported by Wuet al. (2001), that there was lower \%body fat among adult men of all ages but this fat is usually located in the abdomen.

Lack of regular physical activity has been shown to confer various health hazards on the body. The outcome of this study shows that the participants had low physical activity level and some were moderately disabled. Alzahraniet al. (2019) reported an inverse relationship between low back pain and physical activity participation in a systematic review and meta-analysis of an observational study. Furthermore, LBP individuals with moderate/higher physical activity reported less pain and disability after 12 months of followup (Pinto et al., 2014). The negative effects of pain on physical activity in low back pain patients has been attributed to the deconditioning model of low back pain which results from psychological effects (Storheimet al., 2005), neuromuscular changes (Hammillet al.,2008) and physical functioning changes (Di Lorio et al., 2007) among others.

There was a positive relationship among multifidus fatty infiltration and BMI, \%body fat, visceral mass, disability, pain andgender, whilethe researchers observed a negative relationship between lumbar multifidus fatty infiltration and occupation. A corresponding increase in BMI, gender, \%body fat, visceral mass and disability leads to increase in the lumbar multifidus fatty infiltration as seen from this study. These findings are in line with the previous studies that show that multifidus fat infiltration is associated with BMI (Marcuset al.,2010; Hildebrandtet al.,2017), pain (Hideset al.,2008) and gender (Crawford et al., 2016). However, this is contrary to the findings of previous studies on patients with non-specific acute and CLBP and disc herniation (Konget al.,2014). Furthermore, it was also found that significant relationship existed between severity of LMM fat infiltration and pain intensity $(r=0.22, p=0.02)$, though weak, which was in line with the findings of Storheimet al. (2017) who found that fat infiltration correlated positively with pain intensity and disability patients with CLBP. Similarly, Kjaeret al.(2007) also reported that fatty infiltration in the LMM had a stronger correlation with LBP severity in the adult population than in adolescents. 
BAJOPAS Volume 13 Number 2,December, 2020

Also, a study conducted by Poonam et al.(2016) on the role of MRI and Ultrasonography in the evaluation of multifidus muscle in CLBP patients found a positive correlation between pain severity and fat infiltration in the LMM. Although their study was strictly on CLBP patients, the findings of this study can be explained in terms of small sample size and a combination of both acute and chronic low back pain patients which is why the strength of the correlation was low $(r=0.22, p=0.03)$.Percentage body fat, among other body adiposity indices measured was the only predictor of the lumbar multifidus fat infiltration among low back pain individuals.

This study also shows that there is a positive correlation between percentage body fat and pain intensity $(r=0.73, p=0.001)$. In a large crosssectional study on the relationship between body composition and LBP intensity and disability, a strong relationship between BMI and LBP intensity was found among the general population(Hussain et al., 2017), which is in harmony with the findings of the current study.

The outcome of this study should be interpreted with caution due to its limitations. The duration of the LBP was not taken into consideration while recruiting the participants for this study. Also, since this was a cross-sectional study, the causative effects of covariate and predictors of lumbar multifidus cannot be upheld.

\section{REFERENCES}

Adom, T., Annazi, de Villers.,Andre,P.K., \&Thandi, P. (2017).Prevalence of Obesity and overweight in African learners: A protocol for systematic review and Meta-analysis. $B M J$ Open, (7):e013538.

Akindele, M. O., Phillips, J. S., \&Igumbor, E. U. (2016). The Relationship Between Body Fat Percentage and Body Mass Index in Overweight and Obese Individuals in an Urban African Setting. Journal of Public Health in Africa, $\quad \pi 1$, 515. https://doi.org/10.4081/jphia.2016.515

Alzahrani, H., Mackey, M., Stamatakis, E., Zadro, J. R., \& Shirley, D. (2019). The association between physical activity and low back pain: a systematic review and meta-analysis of observational studies. Scientific reports, $9(1)$, 8244. https://doi.org/10.1038/s41598-01944664-8

Bello B, \&Adebayo H. (2017). A Systematic Review on the Prevalence of Low Back Pain in Nigeria,

\section{CONCLUSION}

The outcome of this study shows that there were gender differences in the body adiposities of the study participants. In addition, an increase in BMI, gender, \%body fat, visceral mass, ODI and VAS leads to a corresponding increase in the lumbar multifidus fatty infiltration while the best correlate of lumbar multifidus fatty infiltration was \%body fat.

\section{ACKNOWLEDGEMENT}

The authors thank all the participants and the management of Aminu Kano Teaching Hospital for their supports.

\section{Authors' contribution}

Study concept and design: MukadasAkindele, YamsatNandom Aaron

Data collection: YamsatNandom Aaron, MukadasAkindele, Musa Yusuf Dambele, Sarafadeen Raheem

Data entry, cleaning and analysis: YamsatNandom Aaron, MukadasAkindele, Musa Yusuf Dambele

Manuscript drafting: MukadasAkindele, Musa Yusuf Dambele

Critique of the draft: Sarafadeen Raheem

Funding/Support: None

Conflict of interest: The authors declare no conflict of interest

Informed consent: All the participants fill informed consent forms

Middle East $J$ Rehabil Health Stud. 4(2),e45262. doi: 10.5812/mejrh.45262.

Campbell, W. W., Vasconcelos, O., \&Laine, F. J. (1998). Focal atrophy of the multifidus muscle in lumbosacral radiculopathy. Muscle \& nerve, 21(10), $1350-1353$. https://doi.org/10.1002/(sici)10974598(199810)21:10<1350::aidmus2 $1>3.0 .00 ; 2-4$

Crawford, R. J., Filli, L., Elliott, J. M., Nanz, D., Fischer, M. A., Marcon, M., \&Ulbrich, E. J. (2016). Age- and Level-Dependence of Fatty Infiltration in Lumbar Paravertebral Muscles of Healthy Volunteers. AJNR. American Journal of Neuroradiology, 374), 742-748. https://doi.org/10.3174/ajnr.A4596

Di Lorio, A., Abate, M., Guralnik, J. M., Bandinelli, S., Cecchi, F., Cherubini, A., Corsonello, A., Foschini, N., Guglielmi, M., Lauretani, F., Volpato, S., Abate, G., \&Ferrucci, L. (2007). From chronic low back pain to disability, a multifactorial mediated pathway: the InCHIANTI study. Spine, 32(26), E809-E815. 
BAJOPAS Volume 13 Number 2,December, 2020 https://doi.org/10.1097/BRS.0b013e31815cd4 22

Hammill, R. R., Beazell, J. R., \& Hart, J. M. (2008). Neuromuscular consequences of low back pain and core dysfunction. Clinics in sports medicine, 273), 449-ix. https://doi.org/10.1016/j.csm.2008.02.005

Hartvigsen, J., Hancock, M. J., Kongsted, A., Louw, Q., Ferreira, M. L., Genevay, S., Hoy, D., Karppinen, J., Pransky, G., Sieper, J., Smeets, R. J., Underwood, M., \& Lancet Low Back Pain Series Working Group (2018). What low back pain is and why we need to pay attention. Lancet (London, England), 391(10137), 2356-2367. https://doi.org/10.1016/S01406736(18)30480-X

Hides, J. A., Richardson, C. A., \& Jull, G. A. (1996). Multifidus muscle recovery is not automatic after resolution of acute, firstepisode low back pain. Spine, 21(23), 2763$2769 . \quad$ https://doi.org/10.1097/00007632199612010-00011

Hides, J., Gilmore, C., Stanton, W., \&Bohlscheid, E. (2008). Multifidus size and symmetry among chronic LBP and healthy asymptomatic subjects. Manual Therapy, 13(1), 43-49. https://doi.org/10.1016/j.math.2006.07.017

Hildebrandt, M., Fankhauser, G., Meichtry, A., \&Luomajoki, H. (2017). Correlation between lumbar dysfunction and fat infiltration in lumbar multifidus muscles in patients with low back pain. BMC Musculoskeletal Disorders, 18(1), 12. doi:10.1186/s12891-0161376-1

Hodges, P. W. \& Richardson, C. A. (1998). Delayed postural contraction of transversus abdominis in low back pain associated with movement of the lower limb. J Spinal Disord, 11, 46-56.

Hodges, P. W. \& Richardson, C. A. (1999). Altered trunk muscle recruitment in people with low back pain with upper limb movement at different speeds. Archives of Physical Medicine and Rehabilitation, 80, 1005-1012.

Hodges, P., van den Hoorn, W., Dawson, A., \&Cholewicki, J. (2009). Changes in the mechanical properties of the trunk in low back pain may be associated with recurrence. Journal of Biomechanics, 42(1), 61-66. https://doi.org/10.1016/j.jbiomech.2008.10.00 1

Hoy, D. G., Smith, E., Cross, M., Sanchez-Riera, L., Blyth, F. M., Buchbinder, R., Woolf, A. D., Driscoll, T., Brooks, P., \& March, L. M. (2015).
Reflecting on the global burden of musculoskeletal conditions: lessons learnt from the global burden of disease 2010 study and the next steps forward. Annals of the Rheumatic Diseases, 74(1), 4-7. https://doi.org/10.1136/annrheumdis-2014205393

Hoy, D., Bain, C., Williams, G., March, L., Brooks, P., Blyth, F., Woolf, A., Vos, T., \&Buchbinder, R. (2012). A systematic review of the global prevalence of low back pain. Arthritis and Rheumatism, 64(6), 2028-2037. https://doi.org/10.1002/art.34347

Hultman, G., Nordin, M., Saraste, H., \&Ohlsèn, H. (1993). Body composition, endurance, strength, cross-sectional area, and density of MM erector spinae in men with and without low back pain. Journal of Spinal Disorders, 6(2), 114-123.

Hussain SM, Urquhart DM, Wang Y, Shaw JE, Magliano DJ, Wluka AE, Cicuttini FM.(2017). Fat mass and fat distribution are associated with low back pain intensity and disability: results from a cohort study. Arthritis Res Ther. 19, 26-10. Doi:10.1186\%2Fs13075-017-1242$\mathrm{z}$

Kalichman L, Hodges P, Li L, Hunter DJ. (2010). Changes in the paraspinal muscles and their association with low back pain and spinal degeneration: CT study. Eur Spine J, 19(7), 1136-1144. Doi: 10.1007/s00586-009-1257-5

Karastergiou, K., Smith, S. R., Greenberg, A. S., \& Fried, S. K. (2012). Sex differences in human adipose tissues - the biology of pear shape. Biology of Sex Differences, 3(1), 13. https://doi.org/10.1186/2042-6410-3-13

Keller, A., Brox, J. I., Gunderson, R., Holm, I., Friis, A., \&Reikerås, O. (2004). Trunk muscle strength, cross-sectional area, and density in patients with chronic low back pain randomized to lumbar fusion or cognitive intervention and exercises. Spine, 29(1), 3-8. https://doi.org/10.1097/01.BRS.0000103946.2 6548.EB

Kjaer P., Bendix T., Sorensen J.S. Korsholm L., \&Leboeuf-Yde C. (2007). Are MRI-defined fat infiltrations in the multifidus muscles associated with low back pain? BMC Med,5(2) https://doi.org/10.1186/1741-7015-5-2

Kong, B. J., Lim, J. S., \& Kim, K. (2014). A study on dispersion and rate of fat infiltration in the lumbar spine of patients with herniated nucleus polpusus. Journal of Physical Therapy Science, 26(1), 37-40. https://doi.org/10.1589/jpts.26.37 
BAJOPAS Volume 13 Number 2,December, 2020

Le Huec, J. C., Mathews, H., Basso, Y., Aunoble, S., Hoste, D., Bley, B., \&Friesem, T. (2005). Clinical results of Maverick lumbar total disc replacement: two-year prospective follow-up. The Orthopedic clinics of North America, 36(3), 315-322. https://doi.org/10.1016/j.ocl.2005.02.001

Louw Q.A., Morris L.D., \&Grimmer-Somers K. (2007). The prevalence of low back pain in Africa:A systematic review. BMC Musculoskeletal Disorders, 8, 105. Doi: 10.1186/1471-2474-8-105

Luomajoki, H., \& Moseley, G. L. (2011). Tactile acuity and lumbopelvic motor control in patients with back pain and healthy controls. British Journal of Sports Medicine, 45(5), 437440.

https://doi.org/10.1136/bjsm.2009.060731

Mannion A. F. (1999). Fibre type characteristics and function of the human paraspinal muscles: normal values and changes in association with low back pain. Journal of electromyography and kinesiology: official journal of the International Society of Electrophysiological Kinesiology, 9(6), 363377. https://doi.org/10.1016/s10506411(99)00010-3

Marcus, R. L., Addison, O., Kidde, J. P., Dibble, L. E., \&Lastayo, P. C. (2010). Skeletal muscle fat infiltration: impact of age, inactivity, and exercise. The journal of Nutrition, Health \& Aging, 14(5), 362-366. https://doi.org/10.1007/s12603-010-0081-2

Mok, N. W., Brauer, S. G., \& Hodges, P. W. (2007). Failure to use movement in postural strategies leads to increased spinal displacement in low back pain. Spine, 32(19), E537-E543.

https://doi.org/10.1097/BRS.0b013e31814541 a2

O'Sullivan, P. B., Burnett, A., Floyd, A. N., Gadsdon, K., Logiudice, J., Miller, D., \& Quirke, H. (2003). Lumbar repositioning deficit in a specific low back pain population. Spine, 28(10), 1074-1079. https://doi.org/10.1097/01.BRS.0000061990.5 6113.6F

Panjabi M. M. (1992). The stabilizing system of the spine. Part I. Function, dysfunction, adaptation, and enhancement. Journal of Spinal Disorders, 5(4), 383-397. https://doi.org/10.1097/00002517199212000-00001
Pinto, R. Z., Ferreira, P. H., Kongsted, A., Ferreira, M. L., Maher, C. G., \& Kent, P. (2014). Selfreported moderate-to-vigorous leisure time physical activity predicts less pain and disability over 12 months in chronic and persistent low back pain. European journal of Pain (London, England), 18(8), 1190-1198. https://doi.org/10.1002/j.15322149.2014.00468.x

Ramond-Roquin, A., Bouton, C., Bègue, C., Petit, A., Roquelaure, Y., \&Huez, J. F. (2015). Psychosocial Risk Factors, Interventions, and Comorbidity in Patients with Non-Specific Low Back Pain in Primary Care: Need for Comprehensive and Patient-Centered Care. Frontiers in Medicine, 2, 73. https://doi.org/10.3389/fmed.2015.00073

Storheim, K., Berg, L., Hellum, C., Gjertsen, Ø.,Neckelmann, G., Espeland, A., Keller, A., \& Norwegian Spine Study Group (2017). Fat in the lumbar multifidus muscles - predictive value and change following disc prosthesis surgery and multidisciplinary rehabilitation in patients with chronic low back pain and degenerative disc: 2-year follow-up of a randomized trial. BMC Musculoskeletal Disorders, 18(1), 145. https://doi.org/10.1186/s12891-017-1505-5

Storheim, K., Brox, J. I., Holm, I., \&Bø, K. (2005). Predictors of return to work in patients sick listed for sub-acute low back pain: a 12-month follow-up study. Journal of Rehabilitation Medicine, 376), 365-371. https://doi.org/10.1080/16501970510040344

Vohra P, Kasana VP, Arya RK. (2016). Role of MRI and ultrasonography in evaluation of multifidus muscle in chronic low back pain patients. IJRMS, 4(12), 5302-5309. Doi:http://dx.doi.org/10.18203/23206012.ijrms20164199

Wand, B. M., Parkitny, L., O'Connell, N. E., Luomajoki, H., McAuley, J. H., Thacker, M., \& Moseley, G. L. (2011). Cortical changes in chronic low back pain: current state of the art and implications for clinical practice. Manual Therapy, 16(1), 15-20. https://doi.org/10.1016/j.math.2010.06.008

Wu, C. H., Yao, W. J., Lu, F. H., Yang, Y. C., Wu, J. S., Chang, C. J. (2001) Sex differences of body fat distribution and cardiovascular dysmetabolic factors in old age. Age Ageing. 30: 331- 336 . 